\title{
The Direct Anterior Approach to the Hip Joint
}

\author{
K Mohan Iyer* \\ Senior Consultant Orthopaedic Surgeon, India
}

Submission: November 28, 2017; Published: December 12, 2017

*Corresponding author: K Mohan Iyer, Senior Consultant Orthopaedic Surgeon, Bangalore, India, (Formerly Royal Free Hampstead NHS Trust, Royal Free Hospital, Pond Street, London NW3 2QG, United Kingdom, Email: kmiyer28@hotmail.com

Introduction

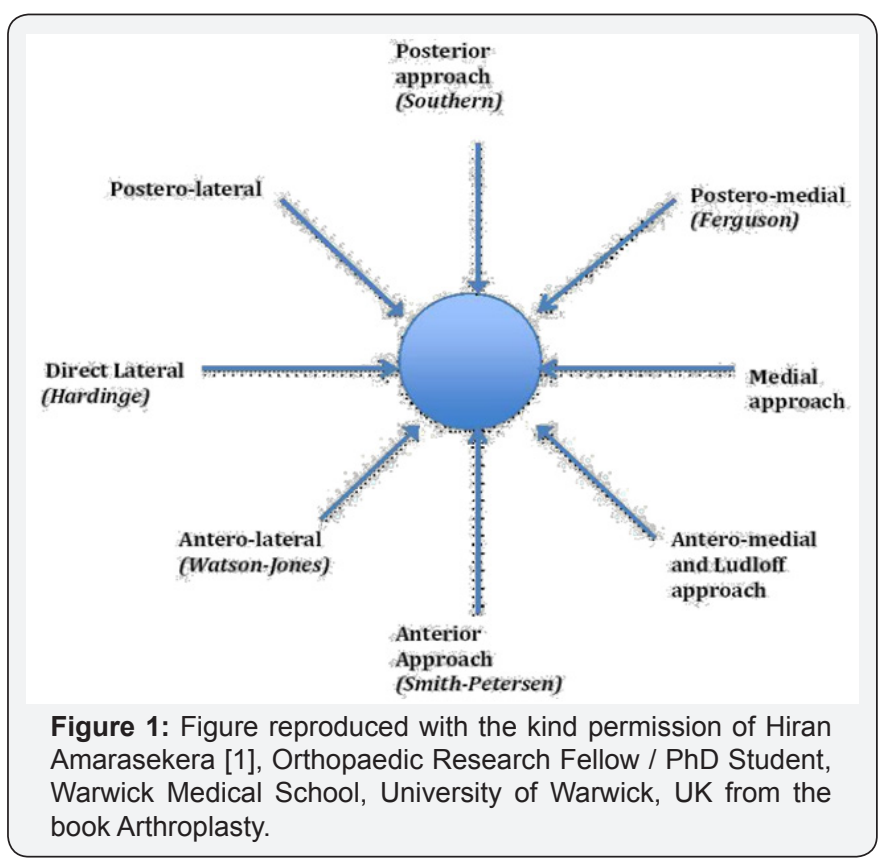

One of the most significant advancements in total hip replacement is that the procedure can be done with much less invasive techniques which allow the patient to recover faster. Minimally invasive surgical techniques have become an important component of modern hip replacements. These techniques require minimisation of damage to periarticular soft tissues and conservation of bone substance to the extent possible. The prerequisite for these requirements is the development of an end prosthesis whose stem is designed both to conserve bone mass and to largely avoid damage to soft tissues, which permits faster restoration of hip function [1]. The most effective surgical approach for the Hip Joint remains controversial, as the Hip joint is likened to a motorway roundabout with numerous approaches and exits. There are more than 100 different approaches to the Hip Joint described in literature (Figure 1).

I had devised an Approach to the Hip Joint 'Modified Posterior Approach to the Hip Joint' https://www.morebooks.de/ store/gb/book/modified-posterior-approach-to-the-hip- joint/ isbn/978-3-330-33687-2 in 1981 after cadaveric tests prior to clinical application in patients and have was using it till to date. I had devised the Modified Posterior Approach to the Hip Joint along with the guidance of a Biomedical Engineer Dr. Martin Elloy, PhD attached, to the University of Liverpool, UK, at a time when there were considerable reports of dislocation of the hip joint using the conventional posterior Approach as described by Austin Moore in 1957 [2]. Since I had been using this Modified Posterior Approach to the Hip Joint mainly for this reason, I had started using the Direct Anterior Approach to the Hip Joint since early 2017, and I came to the conclusion that it served the same purpose as that when I had devised the Modified Posterior Approach, with no need to osteotomise the greater trochanter and hence avoid any complications related to the union of the greater trochanter, such as non-union or fibrous union.

In view of these multiple advantages offered by this Approach, I would certainly recommend this Direct Anterior Approach to the Hip Joint to the newer generation of Orthopaedic Surgeons wherever feasible. Of late in early 2017, after my interaction with Dr. John O'Donnell of Australia who uses a fracture table for DAA (Figure 2) does not hesitate saying that I continue to use DAA for my hip replacements, and I have been very happy with it. I cannot really imagine changing to any other approach now [3]. I have developed an interest in the Direct Anterior Approach to the Hip Joint and have used in initially in Hemiarthroplasty in a few cases with a radical change in my thinking of this Approach, which I appreciate very much for the patients benefit.

Certain conventional procedures were replaced when the approach was modified to avoid trochanteric osteotomy where in antero lateral minimally invasive approach (ALM) has been described as a good alternative to traditional approaches as it reduces hospital stay, surgical time, blood loss, morbidity, and encourages early mobilisations, and recovery. This is an approach with many advantages in the modern day practice. However this is a technically demanding procedure that needs expertise. True AMIS Minimally Invasive Surgery is characterized 


\section{Orthopedics and Rheumatology Open Access Journal}

by the preservation of muscles and tendons encountered during the surgery AND no muscles or tendons are cut. The blood loss is reduced and the pain is minimized. The approach to the hip joint offers a reduced skin incision of only 6-8 $\mathrm{cm}$. Direct anterior hip replacement is a minimally invasive surgical technique. The anterior approach for hip replacement is a tissue-sparing technique designed to follow both an intermuscular and an internervous path.

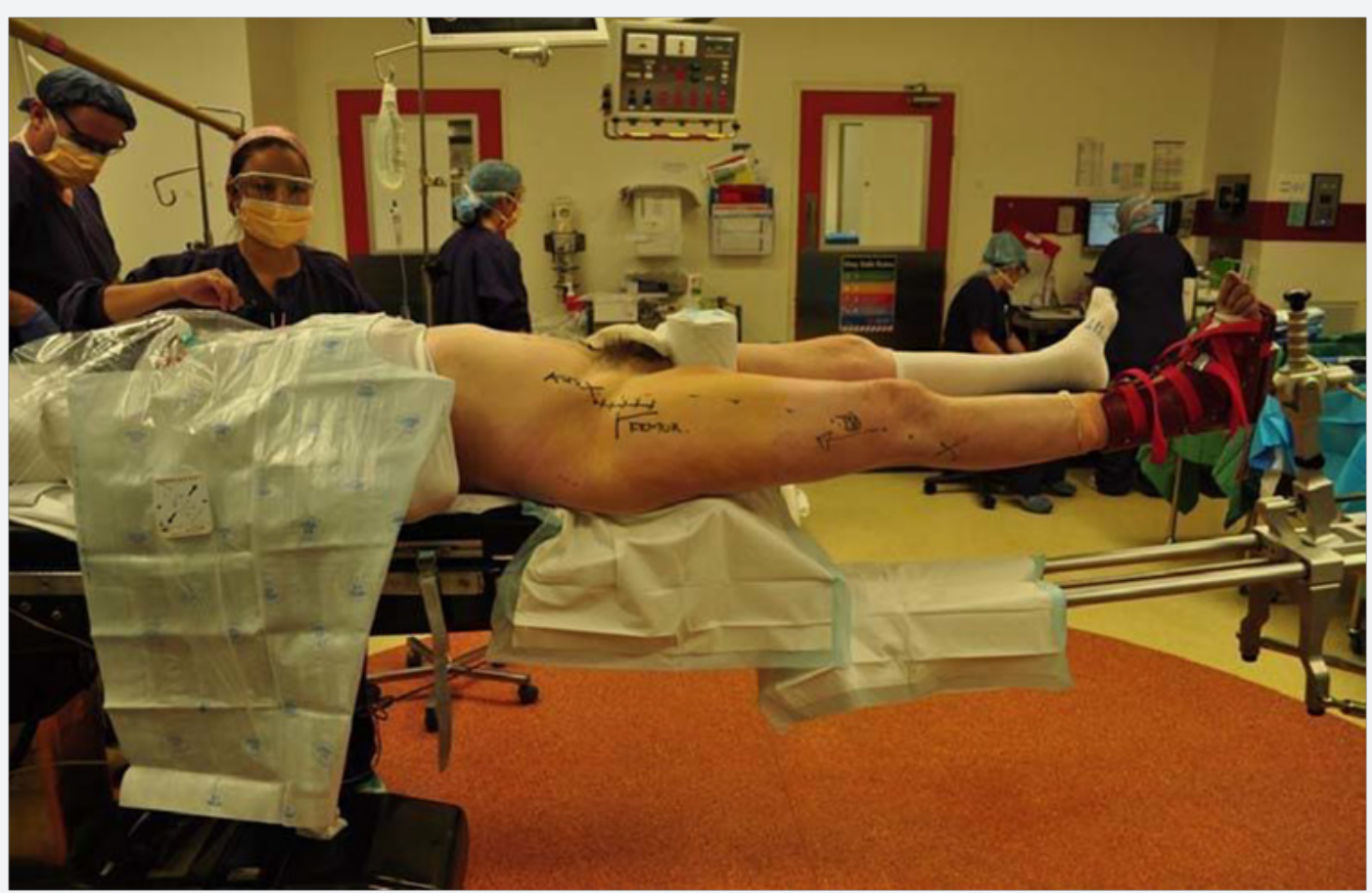

Figure 2: Patient positioned for right Total Hip Replacement (“Courtesy: With the kind permission of Dr. John O D'onnell, Associate Professor, Hip Arthroscopy Australia).

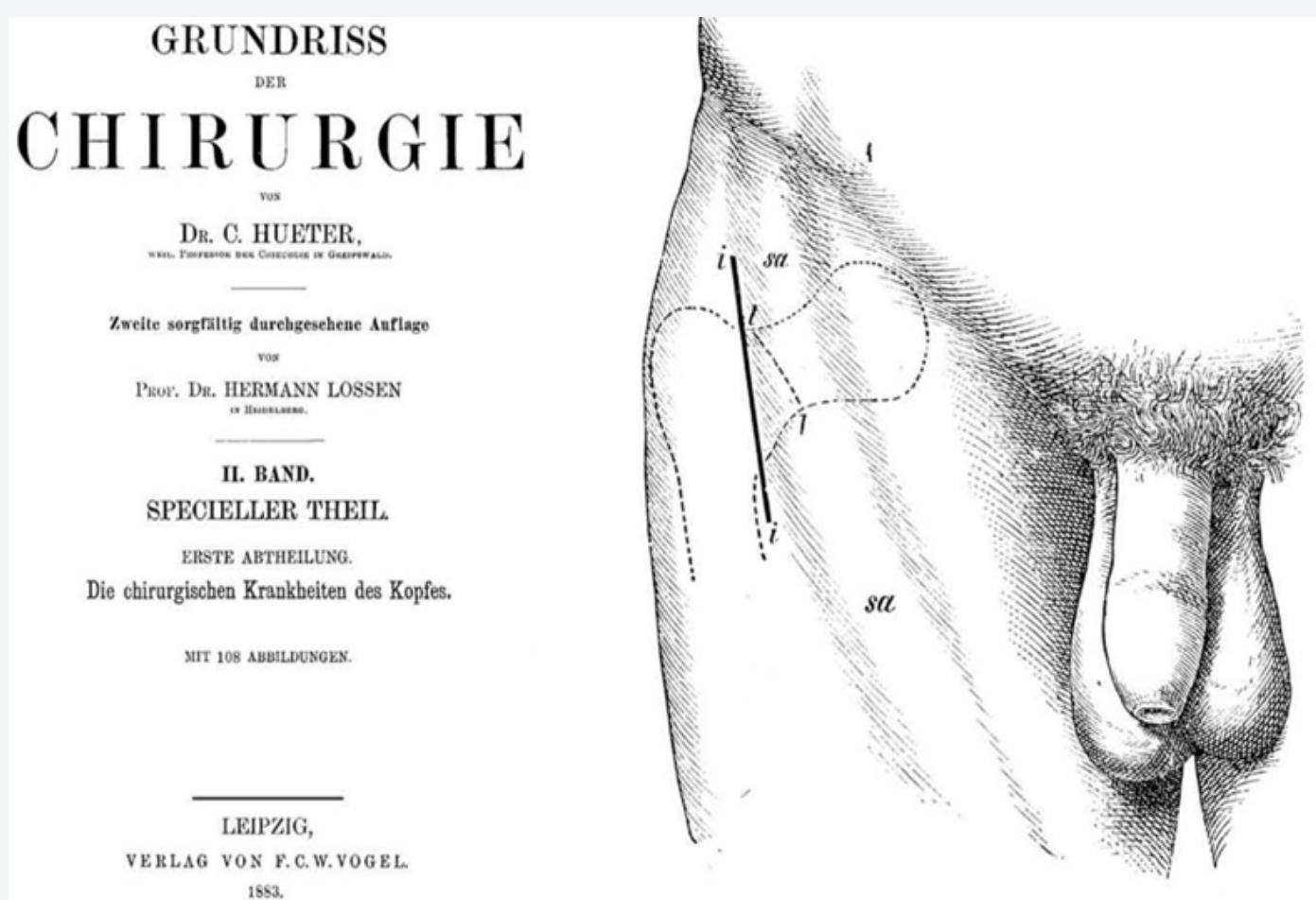

Figure 3: Hueter's original publication. 


\section{Orthopedics and Rheumatology Open Access Journal}

Direct anterior approach (DAA) has recently gained popularity in United States for past one decade as "minimally invasive muscle sparing approach" The first description [4] of the direct anterior approach to the hip joint (Figure 3). This approach provides a direct view of the acetabulum with visualization of the anterior iliac spine landmarks to allow reference for appropriate cup positioning. It utilizes anterior internervous and intermuscular plane. The excellent exposure of the hip joint which they provide, make them an invaluable asset in each surgeon's arsenal, whether he performs a primary or a revision total hip arthroplasty. In contrast with conventional techniques, direct anterior approaches (DAA) seem to currently grow popularity among the orthopaedic hip surgeons and patients.

This has even progressed to the point that some patients are able to have their surgery accomplished as an outpatient procedure, as mentioned in my book "Hip Joint in Adults: Advances and Developments" https://www.crcpress.com/HipJoint-in-Adults-Advances.

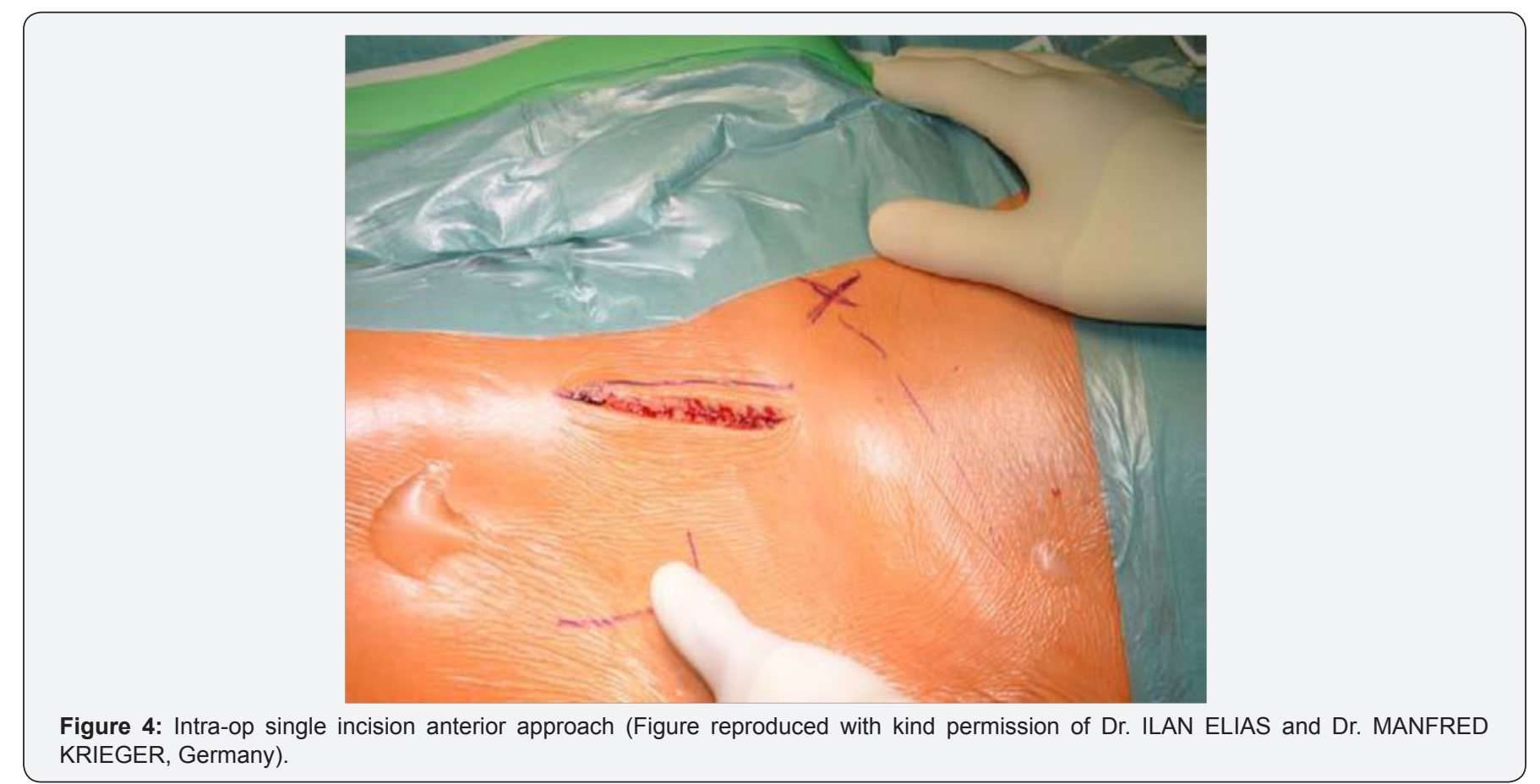

Developments/lyer/p/book/9789814774727 in chapter 18 as "Total hip in a day, setup and early experiences in outpatient hip surgery", by Dr. Med. Manfred Krieger and Dr. Med. Ilan Elias, Wiesbaden, Frankfurt, Germany [5]. This is a revolutionary chapter written wherein a Total Hip can be done as an outpatient procedure (Figure 4) on selected patients in a day.

This DAA can be used in

i. Outpatient procedure as in certain advanced centres in Frankfurt, Germany.

ii. The Direct Anterior Approach in Hemiarthroplasty.

iii. Direct Anterior Approach in Primary Total Hip Arthroplasty.

iv. Direct Anterior Approach in Revision Hip Arthroplasty.

I have tried to get accustomed to this DAA by initially doing a few cases of Hemiarthroplasty as shown in Figure 4, and am convinced of the usefulness of this Approach to the Hip Joint for the younger generation of Orthopaedic Surgeons in the world, because of multiple advantages.
Dr. John 0 D'onnell, Associate Professor, Hip Arthroscopy Australia is also the Convener and Host, Melbourne ISHA ASM 2018,and would encourage all Orthopaedic Surgeons worldwide to attend the same.

\section{References}

1. Figure reproduced with the kind permission of Hiran Amarasekera, Orthopaedic Research Fellow, PhD Student, Warwick Medical School, University of Warwick, UK.

2. Moore AT (1957) The self locking metal Hip Prosthesis. J Bone Jt Surg 39A(4): 811-827.

3. Direct Anterior Approach to the Hip Joint, by John O'Donnell, Hip Joint in Adults: Advances and Developments (2018) Pan Stanford Publishing, Singapore.

4. Hueter C (1883) Funfte abtheilung: die verletzung und krankheiten des huftgelenkes neunundzwnzigtes capitel. Grundriss der chirurgie. $\left(2^{\text {nd }} e d n\right)$, FCW Vogel, Germany, pp. 129-200.

5. Manfred Krieger, Ilan Elias (2018) Total hip in a day, setup and early experiences in outpatient hip surgery, Hip Joint in Adults: Advances and Developments. Pan Stanford Publishing, Singapore. 


\section{Your next submission with Juniper Publishers} will reach you the below assets

- Quality Editorial service

- Swift Peer Review

- Reprints availability

- E-prints Service

- Manuscript Podcast for convenient understanding

- Global attainment for your research

- Manuscript accessibility in different formats

( Pdf, E-pub, Full Text, Audio)

- Unceasing customer service

Track the below URL for one-step submission https://juniperpublishers.com/online-submission.php 